Article

\title{
Synthesis, Structural Characterization and Hirshfeld Surface Analysis of a 2D Coordination Polymer, [Co(4-dpds)(bdc) $\left.\left(\mathrm{H}_{2} \mathrm{O}\right)_{2}\right]$ 4-dpds
}

\author{
Chih-Chieh Wang ${ }^{1, * \mathbb{D}}$, Zi-Ling Huang ${ }^{1}$, Yueh-Yi Tseng ${ }^{1}$, Gia-Bin Sheu ${ }^{1}$, Shih-I Lu ${ }^{1, *}$, \\ Gene-Hsiang Lee ${ }^{2}$ and Hwo-Shuenn Sheu ${ }^{3}$ \\ 1 Department of Chemistry, Soochow University, Taipei 11102, Taiwan; wendyhung51@gmail.com (Z.-L.H.); \\ lunar24575559@gmail.com (Y.-Y.T.); Ben83461@gmail.com (G.-B.S.) \\ 2 Instrumentation Center, National Taiwan University, Taipei 10617, Taiwan; ghlee@ntu.edu.tw \\ 3 National Synchrotron Radiation Research Center, Hsinchu 30076, Taiwan; hsheu@nsrrc.org.tw \\ * Correspondence: ccwang@scu.edu.tw (C.-C.W.); shih_i_lu@hotmail.com (S.-I.L.); \\ Tel.: +886-2-28819471 (ext. 6828) (C.-C.W.)
}

Received: 29 April 2020; Accepted: 22 May 2020; Published: 24 May 2020

\begin{abstract}
A two-dimensional (2D) coordination polymer, [Co(4-dpds) $\left.(\mathrm{bdc})\left(\mathrm{H}_{2} \mathrm{O}\right)_{2}\right] \cdot 4$-dpds (1) (4-dpds $=4,4^{\prime}$-dipyridyldusulfide and $\mathrm{bdc}^{2-}=$ dianion of benzenedicarboxylic acid), has been synthesized and structurally determined by single-crystal X-ray diffractometer. In 1, the bdc ${ }^{2-}$ and 4-dpds both act as bridging ligands connecting the $\mathrm{Co}(\mathrm{II})$ ions to form a 2D wrinkled-like layered coordination polymer. Two wrinkled-like layered coordination polymers are mutually penetrated to generate a doubly interpenetrated framework, and then extended to its 3D architecture via the supramolecular forces between doubly interpenetrated 2D frameworks and free 4-dpds ligands by intermolecular $\mathrm{O}-\mathrm{H} \cdots \mathrm{N}$ hydrogen bonding interaction. Crystal packing arrangements were characterized by fingerprint plots, which were derived from the Hirshfeld Surfaces analysis, and showed that intermolecular hydrogen bonding interactions are the most important interactions on the construction of the crystal 1.
\end{abstract}

Keywords: coordination polymer; metal-organic framework; Hirshfeld surface analysis; hydrogen bond; pi-pi interaction

\section{Introduction}

The three-dimensional (3D) structure constructed by coordination polymers [1] or metal organic frameworks (MOFs) [1,2] with various types of structural topologies have been widely studied, not only on their structural diversity [3-12], but also on their potential functional applications. Based on the concepts of crystal engineering, a variety of supramolecular architectures have been built up through different types of supramolecular forces, ranging from strong halogen interactions [13-21] or hydrogen bonding interaction [22], and much weaker forces, such as weak hydrogen bonding $[23,24]$ and $\pi-\pi$ stacking interactions [25-28]. The $\mathrm{N}, \mathrm{N}^{\prime}$-donor spacer, 4,4'-dipyridyldisulfide (4-dpds), is an excellent ligand for structural research, as it exists as an equilibrium mixture of two enantiomeric conformers with different helicity as $\mathrm{M}$ - and P-forms. The structural diversity of [M(4dpds)] coordination polymers is mainly a result of the characteristic structure of 4-dpds, but is also correlated with the coordination geometry of the metal ions [29-31]. In the present study, we report here the synthesis, structural characteristics and thermal stability of a 2D coordination polymer, $\left[\mathrm{Co}(4-\mathrm{dpds})(\mathrm{bdc})\left(\mathrm{H}_{2} \mathrm{O}\right)_{2}\right] \cdot 4$-dpds (1), which is built up by doubly interpenetrated $2 \mathrm{D}$ wrinkled-like layered coordination polymers and guest 4-dpds molecules in an alternate $\mathrm{ABAB}$ arrangement to complete its 3D structure. Hydrogen bonding interactions between the 2D layered coordination polymers and guest 4-dpds play an important role in the construction of its 3D packing array. The Hirshfeld surface analysis [32] provides a powerful 
tool to examine intermolecular interactions, such as hydrogen bonds, close and distant van der Waals contacts and $\mathrm{C}-\mathrm{H} \cdots \pi$ interactions within the crystal. The nature of these interactions in $\mathbf{1}$ is identified when examining crystal packing diagrams by the Hirshfeld surface analysis.

\section{Results and Discussion}

\subsection{Synthetic and Structural Description of (1)}

Compound 1 was synthesized by the reaction of cobalt(II) chloride (Sigma-Aldrich Inc., Taipei, Taiwan), disodium terephthalate $\left(\mathrm{Na}_{2} \mathrm{bdc}\right)$ (Sigma-Aldrich Inc., Taipei, Taiwan) and 4,4'-dipyridyldisulfide (4-dpds) (Sigma-Aldrich Inc., Taipei, Taiwan) in a water solution with molar ratios of 1:1:2, which resulted in the formation of light-pink plate crystals of $\mathbf{1}$, with a chemical formula of [Co(4-dpds) $\left.(\mathrm{bdc})\left(\mathrm{H}_{2} \mathrm{O}\right)_{2}\right] \cdot 4$-dpds. Single-crystal structural determination reveals that 1 is self-assembled by 2D wrinkled-like layered coordination polymers and guest 4-dpds molecules. It is also notable that 1 crystallizes in the Orthorhombic system, space group Fddd. The asymmetric unit of 1 composed of one hexacoordinated Co(II) centers, half of 4-dpds, half bdc ${ }^{2-}$ and one coordinated water molecule, along with half of a 4-dpds free molecule. The coordination environment of $\mathrm{Co}$ (II) in 1 (Figure 1a) reveals that the $\mathrm{Co}$ (II) ion is located at the two-fold axis and bonded to two nitrogen atoms $(\mathrm{N}(1))$ from two 4-dpds ligands at cis position, with a bond length of 2.176(2) $\AA$, two oxygen atoms $(\mathrm{O}(1))$ from two $\mathrm{bdc}^{2-}$ ligands at trans position, with a bond length of 2.071(1) $\AA$ and two water molecules $(\mathrm{O}(3))$ at cis position, with a bond length of 2.123(1) A. Bond lengths and angles around the $\mathrm{Co}(\mathrm{II})$ ion are listed in Table 1 . In compound $1, \mathrm{bdc}^{2-}$ acts as a bridging ligand adopting bis-monodentate coordination mode, connecting the $\mathrm{Co}(\mathrm{II})$ ions to form a $1 \mathrm{D}$ linear chain. Adjacent $1 \mathrm{D}$ chains are connected via the linkage between the $\mathrm{Co}$ (II) ions and gauche 4-dpds ligand (S-C-C-S dihedral angle 93.6(1)) with the bis-monodentate coordination mode, to form a 2D wrinkled-like layered MOF (Figure 1b) along the $c$ axis), which can be viewed in a simplified way as a 4-connected uninodal net with point symmetry (Schläfli symbol) $\left\{4^{4} .6^{2}\right\}$ by using TOPOS $[33,34]$. One intra-layer O-H..O hydrogen bonds with the O...O distance of 2.684(1) Å between coordinated water molecules (O3) and the un-coordinated oxygen atoms (O2) of bdc ${ }^{2-}$ ligands provide extra energy on the stabilization of the 2D MOF. Related parameters about O-H...O hydrogen bonds are listed in Table 2. Interestingly, two 2D wrinkled-like coordination polymers are mutually interpenetrated to generate a doubly interpenetrated 2D framework (Figure 1c), in which a particular eclipsed $\pi-\pi$ arrangement between the inter-layer benzene rings of bdc $^{2-}$ ligands are observed with the ring centroid distance of 3.604(5) $\AA$. Related inter-planar parameters are listed in Table 3. Furthermore, the doubly interpenetrated 2D frameworks and the guest 4-dpds molecules adopting gauche conformation (S-C-C-S dihedral angle 100.5(1)) are held together and arranged in an alternate ABAB manner to complete its 3D structure by supramolecular force (Figure 1d), via the $\mathrm{O}-\mathrm{H} \cdots \mathrm{N}$ hydrogen bond (green dashed lines in Figure 1d), between the coordinated water molecules $(\mathrm{O}(3))$ and nitrogen atoms $(\mathrm{N}(2))$ of guest 4-dpds molecules. Related parameters of $\mathrm{O}-\mathrm{H} \cdots \mathrm{N}$ hydrogen bonds are listed in Table 2. 


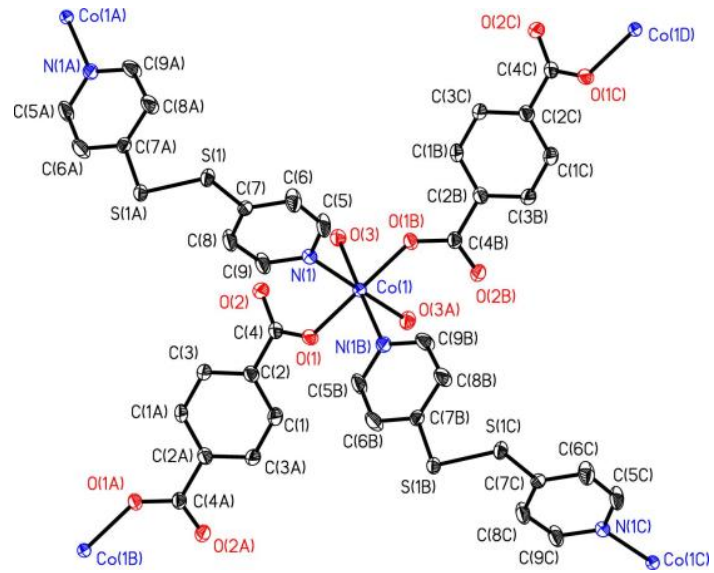

(a)
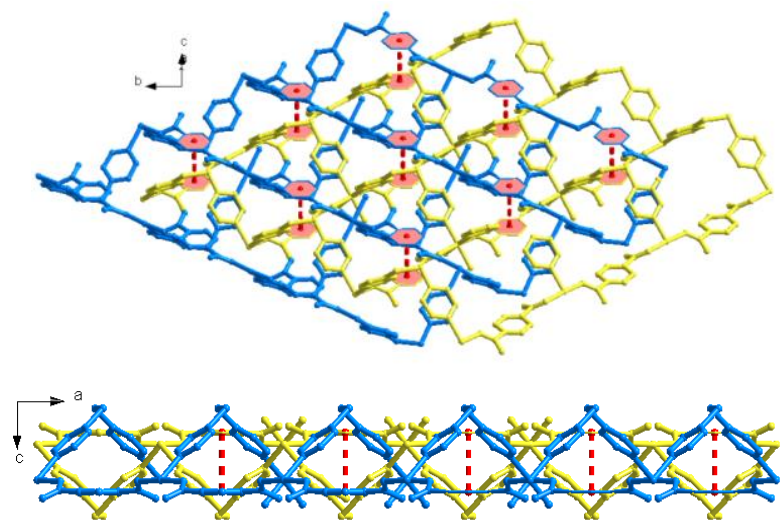

(c)

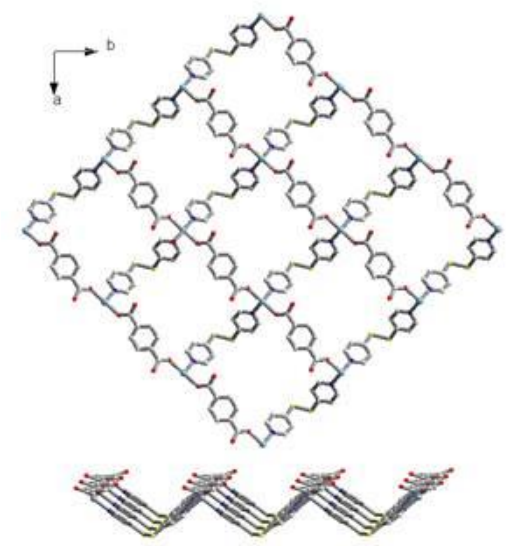

(b)

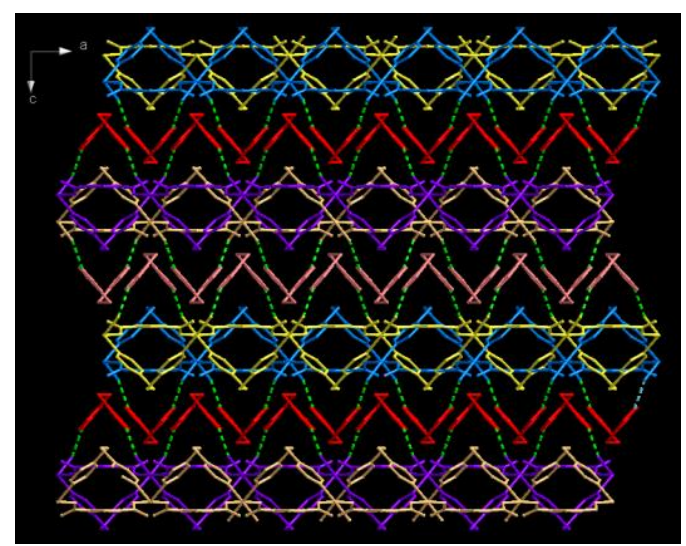

(d)

Figure 1. (a) Coordination geometry of $\mathrm{Co}(\mathrm{II})$ ion in $\mathbf{1}$ with atom labelling scheme (ORTEP drawing, $50 \%$ thermal ellipsoids). Free 4 -dpds and $\mathrm{H}$ atoms are omitted for clarity; (b) the $2 \mathrm{D}$ wrinkled-like coordination polymer viewing along $c$ axis (up) and viewing towards (110) plane (down) in $\mathbf{1}$; (c) the doubly interpenetrated 2D framework in 1 with eclipsed $\pi-\pi$ arrangement between the benzene rings (red color) of $\mathrm{bdc}^{2-}$ ligands viewing along the $a$ axis (up) and $b$ axis (down); (d) the 3D structure assembled by doubly interpenetrated $2 \mathrm{D}$ coordination polymers and guest 4-dpds molecular via the $\mathrm{O}-\mathrm{H} \cdots \mathrm{N}$ hydrogen bonding interaction (green line) viewing along the $b$ axis.

Table 1. Bond lengths $(\AA)$ and angles $\left({ }^{\circ}\right)$ around $\mathrm{Co}(\mathrm{II})$ ion in $1 .^{1}$

\begin{tabular}{cccc}
\hline $\mathrm{Co}(1)-\mathrm{O}(1)$ & $2.071(1)$ & $\mathrm{Co}(1)-\mathrm{O}(1)_{\mathrm{i}}$ & $2.071(1)$ \\
$\mathrm{Co}(1)-\mathrm{O}(3)$ & $2.123(1)$ & $\mathrm{Co}(1)-\mathrm{O}(3)_{\mathrm{i}}$ & $2.123(1)$ \\
$\mathrm{Co}(1)-\mathrm{N}(1)_{\mathrm{i}}$ & $2.176(2)$ & $\mathrm{Co}(1)-\mathrm{N}(1)$ & $2.176(2)$ \\
$\mathrm{O}(1)-\mathrm{Co}(1)-\mathrm{O}(1)_{\mathrm{i}}$ & $175.28(6)$ & $\mathrm{O}(1)-\mathrm{Co}(1)-\mathrm{O}(3)_{\mathrm{i}}$ & $90.52(4)$ \\
$\mathrm{O}(1)-\mathrm{Co}(1)-\mathrm{O}(3)$ & $86.18(4)$ & $\mathrm{O}(1)_{\mathrm{i}}-\mathrm{Co}(1)-\mathrm{O}(3)_{\mathrm{i}}$ & $86.18(4)$ \\
$\mathrm{O}(1)_{\mathrm{i}}-\mathrm{Co}(1)-\mathrm{O}(3)$ & $90.52(4)$ & $\mathrm{O}(3)-\mathrm{Co}(1)-\mathrm{O}(3)_{\mathrm{i}}$ & $91.53(6)$ \\
$\mathrm{O}(1)-\mathrm{Co}(1)-\mathrm{N}(1)_{\mathrm{i}}$ & $93.76(4)$ & $\mathrm{O}(3)_{\mathrm{i}}-\mathrm{Co}(1)-\mathrm{N}(1)_{\mathrm{i}}$ & $86.33(4)$ \\
$\mathrm{O}(1)_{\mathrm{i}}-\mathrm{Co}(1)-\mathrm{N}(1)_{\mathrm{i}}$ & $89.40(4)$ & $\mathrm{O}(1)-\mathrm{Co}(1)-\mathrm{N}(1)$ & $89.40(4)$ \\
$\mathrm{O}(3)-\mathrm{Co}(1)-\mathrm{N}(1)_{\mathrm{i}}$ & $177.86(4)$ & $\mathrm{O}(1)_{\mathrm{i}}-\mathrm{Co}(1)-\mathrm{N}(1)$ & $93.76(4)$ \\
$\mathrm{O}(3)-\mathrm{Co}(1)-\mathrm{N}(1)$ & $86.33(4)$ & $\mathrm{O}(3)_{\mathrm{i}}-\mathrm{Co}(1)-\mathrm{N}(1)$ & $177.86(4)$ \\
$\mathrm{N}(1)_{\mathrm{i}}-\mathrm{Co}(1)-\mathrm{N}(1)$ & $95.81(6)$ & & \\
\hline
\end{tabular}

\footnotetext{
${ }^{1}$ Symmetry transformations used to generate equivalent atoms: $i=-x+7 / 4,-y+3 / 4, z$.
} 
Table 2. Related parameters of $\mathrm{O}-\mathrm{H} \cdots \mathrm{O}$ and $\mathrm{O}-\mathrm{H} \cdots \mathrm{N}$ hydrogen bonds in $\mathbf{1}$.

\begin{tabular}{ccccc}
\hline $\mathbf{D}-\mathbf{H} \cdots \mathbf{A}$ & $\mathbf{D}-\mathbf{H}(\mathbf{A})$ & $\mathbf{H} \cdots \mathbf{A}(\AA)$ & $\mathbf{D} \cdots \mathbf{A}(\AA)$ & $\angle \mathbf{D}-\mathbf{H} \cdots \mathbf{A}\left({ }^{\circ}\right)$ \\
\hline $\mathrm{O}(3)-\mathrm{H}(3 \mathrm{~A}) \cdots \mathrm{N}(2)$ & $0.821(5)$ & $2.045(5)$ & $2.848(2)$ & $166.0(1)$ \\
$\mathrm{O}(3)-\mathrm{H}(3 \mathrm{~B}) \cdots \mathrm{O}(2)$ & $0.806(5)$ & $1.920(5)$ & $2.684(2)$ & $157.9(1)$ \\
\hline
\end{tabular}

Table 3. Related parameters of $\pi-\pi$ interaction in $\mathbf{1}$.

\begin{tabular}{|c|c|c|c|c|}
\hline $\operatorname{Ring(i)}{ }^{a} \rightarrow \operatorname{Ring(j)}{ }^{a}$ & Slip Angle $(i, j) /{ }^{\circ}$ & $\begin{array}{c}\text { Interplanar }(\mathbf{i}, \mathbf{j}) \\
\text { Distance } / \AA\end{array}$ & $\begin{array}{l}\text { Horizontal Shift } \\
\text { between the }(\mathrm{i}, \mathrm{j}) \\
\text { Ring Centroids/A }\end{array}$ & $\begin{array}{c}\text { Distance between } \\
\text { the }(\mathrm{i}, \mathrm{j}) \mathrm{Ring} \\
\text { Centroids/A }\end{array}$ \\
\hline $\mathrm{R}(1) \rightarrow \mathrm{R}(2)$ & 0.0 & $3.604(5)$ & 0.0 & $3.604(5)$ \\
\hline
\end{tabular}

\subsection{Thermal Stability of (1)}

Thermogravimetric analysis (TGA) (Perkin-Elmer 7 Series/UNIX TGA7 analyzer, PerkinElmer, Taipei, Taiwan) and in situ temperature-dependent powder XRD measurements (BL01C2 in National Synchrotron Radiation Research Center (NSRRC), Hsinchu, Taiwan) of $\mathbf{1}$ were performed on the study of its thermal stability and structural variation. The TG profile shown in Figure 2a indicates $\mathbf{1}$ was thermally stable up to $94.3^{\circ} \mathrm{C}$, and then a multi-step but continuous weight loss was observed with the first weight loss of $5.0 \%$ from 94.3 to $117.5^{\circ} \mathrm{C}$, corresponding to the release of two coordinated water molecules (calc 5.1\%). On further heating, samples 1 decomposed at approximately $118-600{ }^{\circ} \mathrm{C}$ with a loss of $81.7 \%$, corresponding to the weight loss of bdc ${ }^{2-}$ and 4-dpds. The structural variation of 1 was further investigated by in situ powder X-ray diffractometry to study the thermal stability as shown in Figure $2 b$. The room temperature powder XRD matched well with the simulation powder pattern from single crystal structure. The powder pattern at room temperature is similar to that at $150{ }^{\circ} \mathrm{C}$. It indicated that the framework was stable till $150^{\circ} \mathrm{C}$. The TGA curve showed that there were two coordinated water losses at $94{ }^{\circ} \mathrm{C}$ to $118^{\circ} \mathrm{C}$. Another large weight was lost at $120^{\circ} \mathrm{C}$ to $230{ }^{\circ} \mathrm{C}$, which indicated that the ligand had decomposed. The powder pattern at $210{ }^{\circ} \mathrm{C}$ showed only a few weak and broad reflections, which indicated the decomposition of the framework structure. The unit cell parameters for powder XRD form RT to $150{ }^{\circ} \mathrm{C}$ are listed in Table 4 . It showed a thermal expansion of the unit cell volume, with the $a$ and $c$ axis becoming longer and the $b$ axis becoming shorter as the temperature heated up. Unit cell parameters were refined by GSAS program. The powder patterns at $210{ }^{\circ} \mathrm{C}, 240{ }^{\circ} \mathrm{C}$ and $270^{\circ} \mathrm{C}$ are similar, and are close to a layer structure. It indicated a one dimensional ordering. The d-spacing of these major XRD patterns are 1/2,1/3, 1/4,1/5, 1/6, 1/7 and 1/8 of $42 \AA$, which may be a compressed $c$ axis. The XRD pattern at $330^{\circ} \mathrm{C}$ showed a new crystalline phase, which did not match any known structure. We used the DICVOL method of the DASH program to index the XRD pattern, which was collected at $330^{\circ} \mathrm{C}$. The major reflections fit a monoclinic cell very well. The index of $330{ }^{\circ} \mathrm{C}$ XRD pattern is shown in Figure 2c. We also used the MATCH program to search the XRD pattern at $480{ }^{\circ} \mathrm{C}$, which matched well with $\mathrm{CoS}$. The Rietveld refinement has applied to refine the $480{ }^{\circ} \mathrm{C}$ XRD pattern. The Rwp and Rp are $0.74 \%$ and $0.42 \%$, respectively, and $\mathrm{X}^{2}$ is 3.65 . The result is shown in Figure 2d. It is clearly demonstrated that the decomposed product is CoS. 


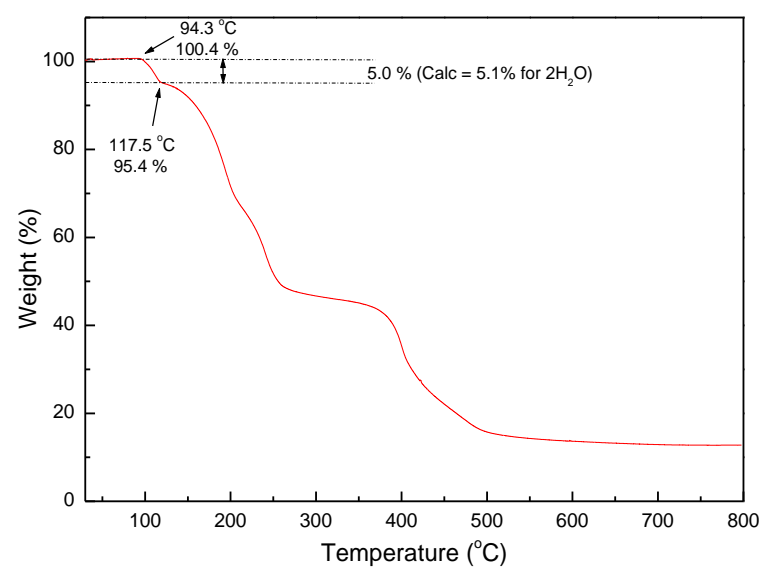

(a)

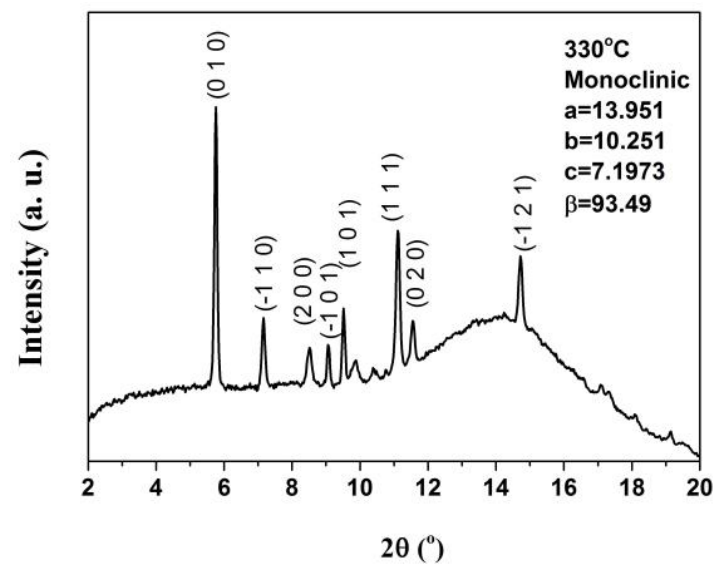

(c)

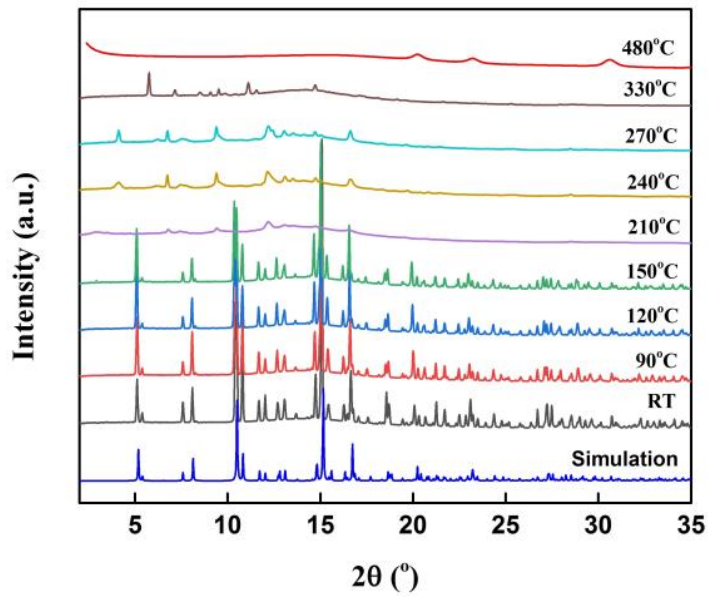

(b)

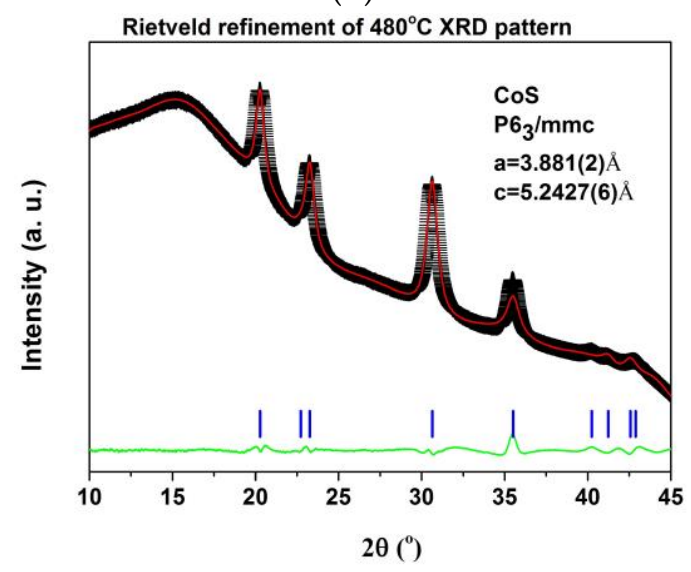

(d)

Figure 2. (a) Thermogravimetric analysis of $\mathbf{1}$. (b) In situ PXRD patterns of $\mathbf{1}$ at different temperatures and simulated PXRD pattern of $\mathbf{1}$ from single-crystal X-ray diffraction data. (c) The XRD pattern collected at $330{ }^{\circ} \mathrm{C}$ can be indexed as a monoclinic cell. Cell parameters are shown in (d) Rietveld refinement of XRD data at $480^{\circ} \mathrm{C}$. The black crosses represent the observed data while the red curve stands for the calculated pattern. The green line at the bottom displays the difference between the observed and calculated patterns and the blue bars indicate the expected Bragg reflection positions. (For interpretation of the references to color in this figure legend, the reader is referred to the web version of this article.).

Table 4. Unit cell parameters of sample 1 determined by single-crystal diffraction and PXRD data.

\begin{tabular}{ccccc}
\hline Compound 1 & $\boldsymbol{a}$ & $\boldsymbol{b}$ & $\boldsymbol{c}$ & Vol \\
\hline Single crystal & $15.3322(4)$ & $16.5790(4)$ & $45.5861(12)$ & $11587.6(5)$ \\
RT & $15.426(1)$ & $16.587(1)$ & $46.059(2)$ & $11785.5(9)$ \\
$90^{\circ} \mathrm{C}$ & $15.4520(6)$ & $16.5776(7)$ & $46.228(1)$ & $11841.6(5)$ \\
$120^{\circ} \mathrm{C}$ & $15.4603(7)$ & $16.5736(9)$ & $46.341(2)$ & $11874.0(6)$ \\
$150^{\circ} \mathrm{C}$ & $15.4686(6)$ & $16.5702(8)$ & $46.450(2)$ & $11905.9(6)$ \\
\hline
\end{tabular}

\subsection{Hirdhfeld Surface Analysis of (1)}

The calculated Hirshfeld surface and subsequent fingerprint plots were used to quantify the intermolecular contacts present within the 3D supramolecular architecture of 1 . Figure 3 gives the 3D Hirshfeld surface showing (i) $\mathrm{O}-\mathrm{H} \cdots \mathrm{N}$ intermolecular hydrogen bonds (ii) $\mathrm{O} \cdots \mathrm{H}-\mathrm{C}$ intermolecular hydrogen bonds and (iii) $\mathrm{S} \cdots \mathrm{H}$ and $\mathrm{S} \cdots \mathrm{O}$ van der Waals interactions. These are indicated as bright red spots on the Hirshfeld surface. The corresponding labels of the three significant interactions are (1), (2) 
and (3), and are noted in Figure 4 as displaying local orientation of one given free dpds among 1a. Here $1 \mathbf{a}$ is the $\left[\mathrm{Co}(4-\mathrm{dpds})(\mathrm{bdc})\left(\mathrm{H}_{2} \mathrm{O}\right)_{2}\right]$ moiety. All are attributed to the interactions between the free 4-dpds and carboxylic groups of $\mathrm{bds}^{-2}$. It appears that the guest 4-dpds locates between two layers of $\mathrm{bdc}^{-2}$ with ordered packing. This proposes that the guest 4-dpds glues the $\left[\mathrm{Co}(4-\mathrm{dpds})(\mathrm{bdc})\left(\mathrm{H}_{2} \mathrm{O}\right)_{2}\right]$ moieties together, and then results in an eclipsed orientation of benzene rings of $\mathrm{bdc}^{-2}$.

(a)

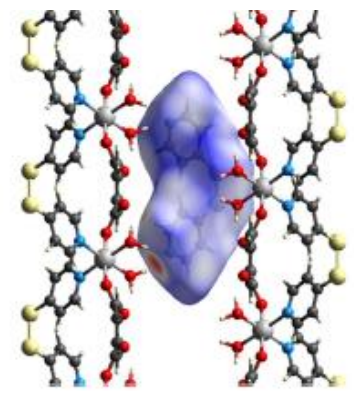

(b)

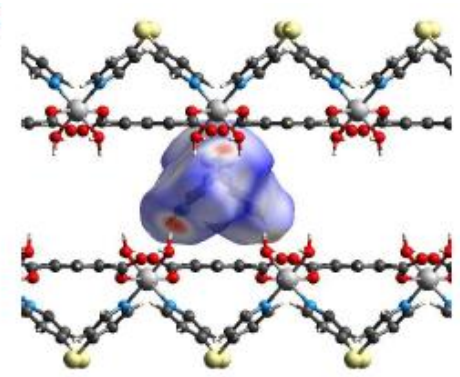

(c)

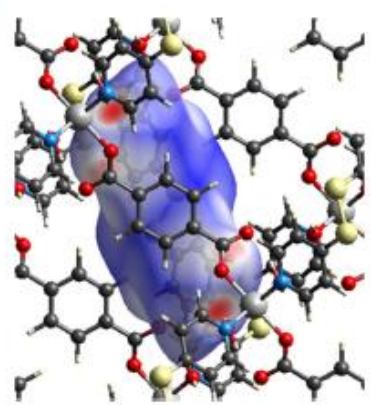

Figure 3. The three-dimensional Hirshfeld surface of the free dpds showing the intermolecular interactions of 1 , plotted over $\mathrm{d}_{\text {norm }}$ viewing from the (a) $a$-axis, (b) $b$-axis and (c) $c$-axis.

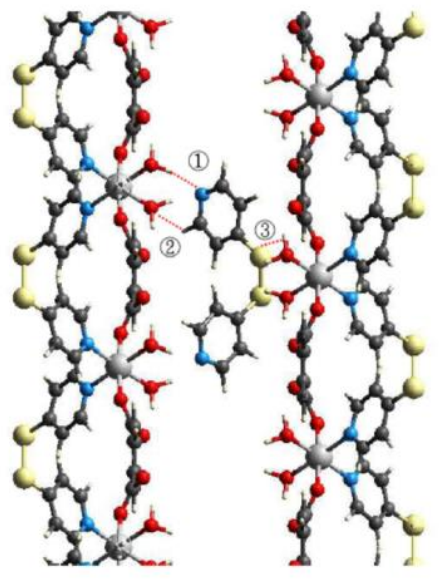

Figure 4. Local orientation of one free 4-dpds among 1 viewed from the $a$-axis.

Significant intermolecular interactions are mapped in Figure 5, showing fingerprint plots and the contributions of atoms within specific interacting pairs (blue area) between the free 4-dpds and 1a. Based on the Hirshfeld surfaces, the $\mathrm{H} \cdots \mathrm{H}$ interactions appear as the largest region $(38.7 \%)$ of the fingerprint plot, with a high concentration at $\mathrm{d}_{\mathrm{e}}=\mathrm{d}_{\mathrm{i}} \sim 1.3 \AA$. The sharp spike $\left(\mathrm{d}_{\mathrm{e}}+\mathrm{d}_{\mathrm{i}} \sim 2.0 \AA\right)$ on the fingerprint plot is observed for $\mathrm{N} \cdots \mathrm{H}$ contact corresponding to the $\mathrm{O}-\mathrm{H} \cdots \mathrm{N}$ interaction. The $\mathrm{O} \cdots \mathrm{H}$ (spiking at $\mathrm{d}_{\mathrm{e}} \sim 1.4 \AA$ and $\mathrm{d}_{\mathrm{i}} \sim 1.0 \AA$ ) and $\mathrm{S} \cdots \mathrm{H}$ contacts contribute to $4.3 \%$ and $7.7 \%$ of the Hirshfeld area, respectively. It is therefore clear that the $\mathrm{N} \cdots \mathrm{H}$ contact is the most important contributor among the interacting atoms for the special eclipsed arrangement of benzene rings of bdc ${ }^{-2}$. 
(a)

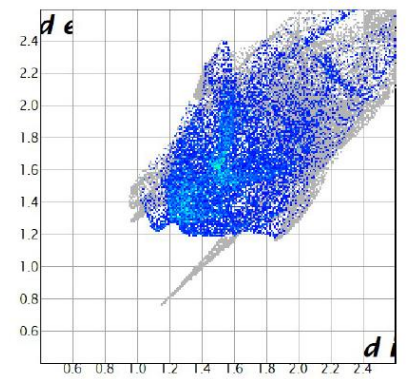

(c)

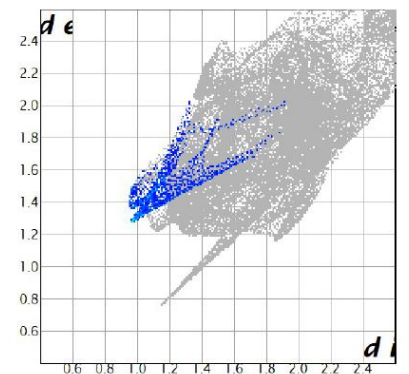

(b)

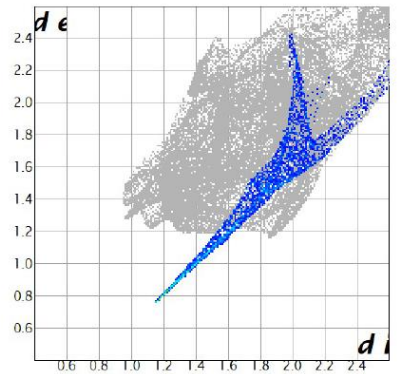

(d)

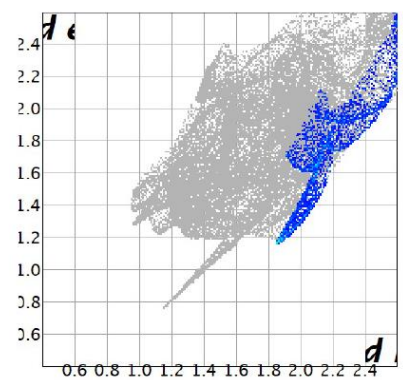

Figure 5. Fingerprint plots of the free 4-dpds, showing the contributions of atoms within specific interacting pairs (blue area). For each fingerprint plot, the grey area is a representation of the whole plot. (a) $\mathrm{H} \cdots \mathrm{H}(38.7 \%)$ (b) $\mathrm{N} \cdots \mathrm{H}(9.7 \%)$ (c) $\mathrm{H} \cdots \mathrm{O}(4.3 \%)$ and (d) $\mathrm{S} \cdots \mathrm{H}(7.7 \%)$.

\section{Experimental Section}

\subsection{Materials and Physical Techniques}

All chemicals were of reagent grade and used as commercially obtained from the SIGMA-ALDRICH company without further purification. Elementary analyses (carbon, hydrogen, and nitrogen) were performed using a Perkin-Elmer 2400 elemental analyzer. IR spectra were recorded on a Nicolet Fourier Transform IR, MAGNA-IR 500 spectrometer in the range of $500-4000 \mathrm{~cm}^{-1}$, using the $\mathrm{KBr}$ disc technique. Thermogravimetric analysis (TGA) of compound $\mathbf{1}$ was performed on a computer-controlled Perkin-Elmer 7 Series/UNIX TGA7 analyzer. Single-phased powder samples were loaded into alumina pans and heated with a ramp rate of $5^{\circ} \mathrm{C} / \mathrm{min}$ from room temperature to $800{ }^{\circ} \mathrm{C}$ under a nitrogen atmosphere.

\subsection{Synthesis of $\left[\mathrm{Co}(4-d p d s)(b d c)\left(\mathrm{H}_{2} \mathrm{O}\right)_{2}\right] \cdot 4-d p d s(1)$}

A water solution $(4 \mathrm{~mL})$ of disodium terephthalate $\left(\mathrm{Na}_{2} \mathrm{BDC}\right)(0.21 \mathrm{~g}, 0.001$ mole) was added to a water solution $(8 \mathrm{~mL})$ of $\mathrm{CoCl}_{2} \cdot 6 \mathrm{H}_{2} \mathrm{O}(0.238 \mathrm{~g}, 0.001 \mathrm{~mole})$ and 4,4'-dipyridyldisulfide (4-dpds) $(0.440 \mathrm{~g}$, 0.002 mole) at RT. After standing for two weeks, light-pink plate crystals of 1 were obtained with yield of $0.4481 \mathrm{~g}(64.1 \%)$. Anal. Calc. for $\mathrm{C}_{28} \mathrm{H}_{24} \mathrm{Co}_{1} \mathrm{~N}_{4} \mathrm{O}_{6} \mathrm{~S}_{4}$ (1): C 48.06, $\mathrm{N}$ 8.01, H 3.46; Found: $\mathrm{C} 48.18$, N 7.91, H 3.37. IR (KBr pellet): $v=1580$ (vs), 1561 (s), 1501 (m), 1482 m), 1415 (s), 1383 (s), 1323 (m), $819(\mathrm{w}), 706(\mathrm{~m}) \mathrm{cm}^{-1}$.

\subsection{Crystallographic Data Collection and Refinements}

A single-crystal structure analysis for compound $\mathbf{1}$ was performed on a Siemens SMART diffractomerter, with a CCD detector with Mo radiation $(\lambda=0.71073 \AA)$ at $150 \mathrm{~K}$. A preliminary orientation matrix and unit cell parameters were determined from 3 runs of 15 frames each, each frame correspond to a $0.3^{\circ} \mathrm{scan}$ in $10 \mathrm{~s}$, following by spot integration and least-squares refinement. For each structure, data were measured using $\omega$ scans of $0.3^{\circ}$ per frame for $20 \mathrm{~s}$, until a complete hemisphere had been collected. Cell parameters were determined using SMART [35] software and refined with SAINT [36] software on all observed reflections. Data reduction was performed with the SAINT [36] software and corrected for Lorentz and polarization effects. Absorption corrections were applied 
with the program SADABS [37]. Direct phase determination and subsequent difference Fourier map synthesis yielded the positions of all non-hydrogen atoms, which were subject to anisotropic refinements. All hydrogen atoms were generated geometrically with the exception of the hydrogen atoms attached to the oxygen atoms of the coordinated water molecules, which were located in the difference Fourier map with the corresponding positions and isotropic displacement parameters being refined. The final full-matrix, least-squares refinement on $F^{2}$ was applied for all observed reflections [I $>2 \sigma(\mathrm{I})]$. All calculations were performed by using the SHELXTL-PC V 5.03 software package [38]. Crystal data and details of the data collection and structure refinements for $\mathbf{1}$ are summarized in Table 5 . CCDC-1998637, for 1 contains the Supplementary Crystallographic Data for this paper. These data can be obtained free of charge [39].

Table 5. Crystal data and details of the data collection and structural refinements of $\mathbf{1}$.

\begin{tabular}{cccc}
\hline Empirical Formula & $\mathbf{C}_{\mathbf{2 8}} \mathbf{H}_{\mathbf{2 4}} \mathbf{C o N}_{\mathbf{4}} \mathbf{O}_{\mathbf{6}} \mathbf{S}_{\mathbf{4}}$ & Formula Mass $\left(\mathbf{g ~ m o l} \mathbf{~ m}^{-\mathbf{1}}\right)$ & $\mathbf{6 9 9 . 6 8}$ \\
\hline crystal system & Orthorhombic & space group & Fddd \\
$a / \AA$ & $15.3322(4)$ & $\alpha\left(^{\circ}\right)$ & 90 \\
$b / \AA$ & $16.5790(4)$ & $\beta\left(^{\circ}\right)$ & 90 \\
$c / \AA$ & $\gamma\left(^{\circ}\right)$ & 90 \\
$V / \AA^{3}$ & $45.5861(12)$ & $\mathrm{Z}$ & 16 \\
$D_{\text {calcd }}\left(\mathrm{g} \mathrm{cm}^{-3}\right)$ & $11587.6(5)$ & $\theta$ range $(\mathrm{deg})$ & $2.252-29.998$ \\
$\mu / \mathrm{mm}^{-1}$ & 1.604 & $\mathrm{~T}(\mathrm{~K})$ & $150(2)$ \\
total no. of data collected & 0.932 & no. of unique data & 4231 \\
$R_{1}, w R_{2}{ }^{1}(\mathrm{I}>2 \sigma(\mathrm{I}))$ & 23999 & $R_{1}, w R_{2}{ }^{1}($ all data) & $0.0344,0.0728$ \\
$\mathrm{GOF}$ & $0.0283,0.0681$ & refine params & 203 \\
\hline${ }^{1} R_{1}=\sum\left\|F_{\mathrm{o}}-F_{\mathrm{c}}\right\| / \sum\left|F_{\mathrm{o}}\right| ; w R_{2}\left(F^{2}\right)=\left[\sum \mathrm{w}\left|F_{\mathrm{o}}{ }^{2}-F_{\mathrm{c}}{ }^{2}\right|^{2} / \sum \mathrm{w}\left(F_{\mathrm{o}}{ }^{4}\right)\right]^{1 / 2} ;{ }^{2} \mathrm{GOF}=\left\{\sum\left[\mathrm{w}\left|F_{\mathrm{o}}{ }^{2}-F_{\mathrm{c}}{ }^{2}\right|^{2}\right] /(n-p)\right\}^{1 / 2}$.
\end{tabular}

\subsection{In Situ X-ray Powder Diffraction of 1}

The powder X-ray diffraction pattern of $\mathbf{1}$ was recorded at the BL01C2 beamline of National Synchrotron Radiation Research Center (NSRRC) in Taiwan. The ring of NSRRC was operated at energy $1.5 \mathrm{GeV}$ with a typical current $300 \mathrm{~mA}$ with top-up injection mode. The wavelength of the incident X-rays was $1.0332 \AA(12.0 \mathrm{KeV})$, delivered from the superconducting wavelength-shifting magnet and a $\mathrm{Si}(111)$ double-crystal monochromator. The diffraction pattern was recorded with a Mar345 imaging-plate detector approximately $300 \mathrm{~mm}$ from the sample. The pixel size of Mar345 was $100 \mu \mathrm{m}$. The resolution is about $0.02^{\circ}$ in $2 \theta$. The $1 \mathrm{D}$ powder diffraction profile was converted with program GSAS-II [40] and cake-type integration. The diffraction angles were calibrated according to Bragg positions of Ag-Benhenate and Si powder (NBS640b) standards. In situ X-ray powder diffractions for 1 were performed from RT to $480{ }^{\circ} \mathrm{C}$, with approximately $4{ }^{\circ} \mathrm{C} /$ min heating rate. The powder samples were sealed in a quartz capillary $(0.5 \mathrm{~mm})$ and heated with a stream of hot air; each in situ PXRD pattern was exposed for about $3 \mathrm{~min}$. In situ PXRD patterns of RT to $150{ }^{\circ} \mathrm{C}$ and $480^{\circ} \mathrm{C}$ were analysis by GSAS program [41]. The unit cell parameters and crystal structures have been refined. PXRD patterns of $210{ }^{\circ} \mathrm{C}$ to $270{ }^{\circ} \mathrm{C}$ were analyzed by the MATCH [42] program. The MATCH program provides search and match of known PXRD patterns for comparison. The diffraction pattern of $330{ }^{\circ} \mathrm{C}$ had been indexed by DIVOL method [43] of the DASH program [44]. It fitted very well with a monoclinic unit cell. The PXRD collected at $480^{\circ} \mathrm{C}$ has been identified by MATCH program. It matched well with the CoS crystal phase. The Rietveld refinement was applied to refine the crystal structure of the $480^{\circ} \mathrm{C}$ data.

\subsection{Computational Details}

Employing the Crystal Explorer program [45], we obtained the Hirshfeld surfaces three-dimensional maps and two-dimensional fingerprint plots to examine the intermolecular contacts within the crystals, especially the interaction between the free dpds and $\mathbf{1 a}$. 


\section{Conclusions}

In this study, we have successfully presented the synthesis, structure, thermal stability and Hirshfeld surface analysis of a 3D coordination compound, [Co(4-dpds) $\left.(\mathrm{bdc})\left(\mathrm{H}_{2} \mathrm{O}\right)_{2}\right] \cdot 4-\mathrm{dpds}(\mathbf{1})$, which is assembled by doubly interpenetrated $2 \mathrm{D}$ wrinkled-like layered coordination polymers and guest 4-dpds molecules. The 4-dpds and $\mathrm{bdc}^{2-}$ both act as bridging ligands connecting the Co(II) ions to form a 2D wrinkled-like coordination polymers. Two coordination polymers were mutually interpenetrated to form a 2D doubly interpenetrated layered framework. The 2D doubly interpenetrated layered coordination polymers and guest 4-dpds molecules were arranged in an alternate ABAB pattern, and were further extended to a $3 \mathrm{D}$ network via an intermolecular hydrogen bonding interaction between the coordinated water molecules and nitrogen atoms of free 4-dpds molecules. The Hirshfeld surface analysis revealed that the $\mathrm{O} \cdots \mathrm{H}, \mathrm{H} \cdots \mathrm{H}, \mathrm{S} \cdots \mathrm{H}$ and $\mathrm{N} \cdots \mathrm{H}$ contacts were the most significant interactions in the crystal of $\mathbf{1}$. The hydrogen bonding information conveyed by the Hirshfeld surface analyses were in consistent with the intermolecular interactions from structural analyses.

Supplementary Materials: The following are available online at http://www.mdpi.com/2073-4352/10/5/419/s1.

Author Contributions: C.-C.W., review and supervision; Z.-L.H., Y.-Y.T. and G.-B.S., synthesis, elementary identification, and TGA; G.-H.L., data collection of single-crystal X-ray diffraction and structural analysis; H.-S.S., data collection of powder XRD; S.-I.L., Hirshfeld surface analysis by theoretical calculation; C.-C.W., S.-I.L. and H.-S.S., wrote the paper. All authors have read and agreed to the published version of the manuscript.

Funding: This research received no external funding.

Acknowledgments: The authors wish to thank the Ministry of Science and Technology for financial support.

Conflicts of Interest: The authors declare no conflict of interest.

\section{References}

1. Batten, S.R.; Champness, N.R.; Chen, X.M.; Garcia-Martinez, J.; Kitagawa, S.; Öhrström, L.; O'keeffe, M.; Suh, M.P.; Reedijk, J. Terminology of metal-organic frameworks and coordination polymers. Pure Appl. Chem. 2013, 85, 1715-1724. [CrossRef]

2. Batten, S.R.; Champness, N.R.; Chen, X.M.; Garcia-Martinez, J.; Kitagawa, S.; Öhrström, L.; O'keeffe, M.; Suh, M.P.; Reedijk, J. Coordination polymers, metal-organic frameworks and the need for terminology guidelines. CrystEngComm 2012, 14, 3001-3004. [CrossRef]

3. O'Keeffe, M.; Peskov, M.A.; Ramsden, S.J.; Yaghi, O.M. The Reticular Chemistry Structure Resource (RCSR) Database of, and Symbols for, Crystal Nets. Acc. Chem. Res. 2008, 41, 1782-1789. [CrossRef] [PubMed]

4. Natarajan, S.; Mahata, P. Metal-organic framework structures-How closely are they related to classical inorganic structures? Chem. Soc. Rev. 2009, 38, 2304-2318. [CrossRef] [PubMed]

5. Blatov, V.A.; O'Keeffe, M.; Proserpio, D.M. Vertex-, face-, point-, Schläfli-, and Delaney-symbols in nets, polyhedra and tilings: Recommended terminology. CrystEngComm 2010, 12, 44-48. [CrossRef]

6. Alexandrov, E.V.; Blatov, V.A.; Kochetkov, A.V.; Proserpio, D.M. Underlying nets in three-periodic coordination polymers: Topology, taxonomy and prediction from a computer-aided analysis of the Cambridge Structural Database. CrystEngComm 2011, 13, 3947-3958. [CrossRef]

7. Baburin, I.A.; Blatov, V.A.; Carlucci, L.; Ciani, G.; Proserpio, D.M. Interpenetrated Three-Dimensional Networks of Hydrogen-Bonded Organic Species: A Systematic Analysis of the Cambridge Structural Database. Cryst. Growth Des. 2008, 8, 519-539. [CrossRef]

8. O'Keeffe, M.; Yaghi, O.M. Deconstructing the Crystal Structures of Metal-Organic Frameworks and Related Materials into Their Underlying Nets. Chem. Rev. 2012, 112, 675-702. [CrossRef]

9. Long, J.R.; Yaghi, O.M. The pervasive chemistry of metal-organic frameworks. Chem. Soc. Rev. 2009, 38, 1213-1314. [CrossRef]

10. Zhou, H.C.; Long, J.R.; Yaghi, O.M. Introduction to Metal-Organic Frameworks. Chem. Rev. 2012, 112, 673-674. [CrossRef]

11. Batten, S.R.; Neville, S.M.; Turner, D.R. Coordination Polymers: Design, Analysis and Application; Royal Society of Chemistry: Cambridge, UK, 2009. 
12. Farrusseng, D. Metal-Organic Frameworks Applications from Catalysis to Gas Storage; Wiley: Weinheim, Germany, 2011.

13. Takamizawa, S.; Akatsuka, T.; Ueda, T. Gas-Conforming Transformability of an Ionic Single-Crystal HostConsisting of Discrete Charged Components. Angew. Chem. Int. Ed. 2008, 47, 1689-1692. [CrossRef] [PubMed]

14. Takamizawa, S.; Kohara, M.; Akatsuka, T.; Miyake, R. Gas-adsorbing ability of tris-ethylenediamine metal complexes (M = Co(III), $\mathrm{Cr}(\mathrm{III}), \mathrm{Rh}(\mathrm{III}), \mathrm{Ir}(\mathrm{III}))$ as transformable ionic single crystal hosts. New J. Chem. 2008, 32, 1782-1787. [CrossRef]

15. Morsali, A.; Masoomi, M.Y. Structures and properties of mercury(II) coordination polymers. Coord. Chem. Rev. 2009, 253, 1882-1905. [CrossRef]

16. Masoomi, M.Y.; Morsali, A. Applications of metal-organic coordination polymers as precursors for preparation of nano-materials Authors. Coord. Chem. Rev. 2012, 256, 2921-2943. [CrossRef]

17. Masoomi, M.Y.; Morsali, A. Morphological study and potential applications of nano metal-organic coordination polymer. RSC Adv. 2013, 3, 19191-19218. [CrossRef]

18. Aslani, A.; Morsali, A.; Zeller, M. Dynamic crystal-to-crystal conversion of a 3D-3D coordination polymer by de- and re-hydration. Dalton Trans. 2008, 5173-5177. [CrossRef]

19. Pan, Q.H.; Li, J.Y.; Chen, Q.; Han, Y.D.; Chang, Z.; Song, W.C.; Bu, X.H. [Co(en $\left.)_{3}\right]_{1 / 3}\left[\operatorname{In}(\text { ox })_{2}\right] \cdot 3.5 \mathrm{H}_{2} \mathrm{O}$ : A zeolitic metal-organic framework templated by $\mathrm{Co}(\mathrm{en})_{3} \mathrm{Cl}_{3}$. Microporous Mesoporous Mater. 2010, 132, 453-457. [CrossRef]

20. Pan, Q.H.; Chen, Q.; Song, W.C.; Hu, T.L.; Bu, X.H. Template-directed synthesis of three new open-framework metal(II) oxalates using Co(III) complex as template. CrystEngComm 2010, 12, 4198-4204. [CrossRef]

21. Bertani, R.; Sgarbossa, P.; Venzo, A.; Lelj, F.; Amati, M.; Resnati, G.; Pilati, T.; Metrangolo, P.; Terraneo, G. Halogen bonding in metal-organic-supramolecular networks. Coord. Chem. Rev. 2010, 254, 677-695. [CrossRef]

22. Ingleson, M.J.; Bacsa, J.; Rosseinsky, M.J. Homochiral H-bonded proline based metal organic frameworks. Chem. Commun. 2007, 27, 3036-3038. [CrossRef]

23. Desiraju, G.R. C-H‥O and other weak hydrogen bonds. From crystal engineering to virtual screening. Chem. Commun. 2005, 25, 2995-3001. [CrossRef] [PubMed]

24. García-Báez, E.V.; Martínez-Martínez, F.J.; Höpfl, H.; Padilla-Martínez, I.I. $\pi$-Stacking Interactions and CH‥X $(\mathrm{X}=\mathrm{O}$, Aryl) Hydrogen Bonding as Directing Features of the Supramolecular Self-Association in 3-Carboxy and 3-Amido Coumarin Derivatives. Cryst. Growth Des. 2003, 3, 35-45. [CrossRef]

25. Janiak, C. A critical account on $\pi-\pi$ stacking in metal complexes with aromatic nitrogen-containing ligands. Dalton Trans. 2000, 3885-3896. [CrossRef]

26. Claessens, C.G.; Stoddart, J.F. $\pi-\pi$ INTERACTIONS IN SELF-ASSEMBLY. J. Phys. Org. Chem. 1997, 10, 254-272. [CrossRef]

27. Guo, H.D.; Guo, X.M.; Batten, S.R.; Song, J.F.; Song, S.Y.; Dang, S.; Zhang, G.L.; Tang, J.K.; Zhang, H.J. Hydrothermal Synthesis, Structures, and Luminescent Properties of Seven $\mathrm{d}^{10}$ Metal-Organic Frameworks Based on 9,9-Dipropylfluorene-2,7-Dicarboxylic Acid ( $\mathrm{H}_{2}$ DFDA). Cryst. Growth Des. 2009, 9, 1394-1401. [CrossRef]

28. Reger, D.L.; Horger, J.J.; Smith, M.D.; Long, G.J.; Grandjean, F. Homochiral, Helical Supramolecular Metal-Organic Frameworks Organized by Strong $\pi \cdots \pi$ Stacking Interactions: Single-Crystal to Single-Crystal Transformations in Closely Packed Solids. Inorg. Chem. 2011, 50, 686-704. [CrossRef] [PubMed]

29. Horikoshi, R.; Mochida, T. Metal complexes of 4, 4'-dipyridyldisulfide-Structural diversity derived from a twisted ligand with axial chirality. Coord. Chem. Rev. 2006, 250, 2595-2609. [CrossRef]

30. Lang, J.P.; Xu, Q.F.; Zhang, W.H.; Li, H.X.; Ren, Z.G.; Chen, J.X.; Zhang, Y. $\mathrm{Mo}(\mathrm{W}) / \mathrm{Cu} / \mathrm{S}$ Cluster-Based Supramolecular Arrays Assembled from Preformed Clusters $\left[\mathrm{Et}_{4} \mathrm{~N}_{4}\left[\mathrm{WS}_{4} \mathrm{Cu}_{4} \mathrm{I}_{6}\right]\right.$ and $\left[(n-\mathrm{Bu})_{4} \mathrm{~N}_{2}\left[\mathrm{MoOS}_{3} \mathrm{Cu}_{3} \mathrm{X}_{3}\right](\mathrm{X}=\mathrm{I}, \mathrm{SCN})\right.$ with Flexible Ditopic Ligands. Inorg. Chem. 2006, 45, 10487-10496. [CrossRef]

31. Ma, L.F.; Wang, L.Y.; Du, M. A novel 3D Mn(II) coordination polymer involving 4,4'-dipyridylsulfide and 4,4'-dipyridyltrisulfide obtained by in situ ligand formation from 4, $4^{\prime}$-dipyridyldisulfide. CrystEngComm 2009, 11, 2593-2596. [CrossRef]

32. Spackman, M.A.; Jayatilaka, D. Hirshfeld surface analysis. CrystEngComm 2009, 11, 19-32. [CrossRef] 
33. Blatov, V.A.; Shevchenko, A.P.; Serezhkin, V.N. TOPOS3.2: A new version of the program package for multipurpose crystal-chemical analysis. J. Appl. Crystallogr. 2000, 33, 1193. [CrossRef]

34. Blatov, V.A.; Carlucci, L.; Ciani, G.; Proserpio, D.M. Interpenetrating metal-organic and inorganic 3D networks: A computer-aided systematic investigation. Part I. Analysis of the Cambridge structural database. CrystEngComm 2004, 6, 377-395. [CrossRef]

35. SMART V 4.043 Software for CCD Detector System; Siemens Analytical Instruments Division: Madison, WI, USA, 1995.

36. SAINT V 4.035 Software for CCD Detector System; Siemens Analytical Instruments Division: Madison, WI, USA, 1995.

37. Sheldrick, G.M. Program for the Refinement of Crystal Structures; University of Göttingen: Göttingen, Germany, 1993.

38. SHELXTL 5.03 (PC-Version), Program Liberary for Structure Solution and Molecular Graphics. Siemens Analytical Instruments Division: Madison, WI, USA, 1995.

39. Cambridge Crystallographic Data Centre. Available online: https://www.ccdc.cam.ac.uk/ (accessed on 29 April 2020).

40. Toby, B.H.; Von Dreele, R.B. GSAS-II: The genesis of a modern open-source all purpose crystallography software package. J. Appl. Crystallogr. 2013, 46, 544-549. [CrossRef]

41. Larson, A.C.; Von Dreele, R.B. General Structure Analysis System (GSAS); Los Alamos National Laboratory Report LAUR 86-748; Los Alamos National Laboratory: Los Alamos, NM, USA, 2000.

42. Putz, H.; Brandenburg, K. Match-Phase Identification from Powder Diffraction; Crystal Impact: Bonn, Germany, 2015. Available online: http://www.crystalimpact.com/match (accessed on 29 April 2020).

43. Boultif, A.; Louer, D. Program for the Automatic Indexing of Powder Diffraction Patterns by the Successive Dichotomy Method. J. Appl. Cryst. 2004, 37, 724-731. [CrossRef]

44. David, W.I.F.; Shankland, K.; van de Streek, J.; Pidcock, E.; Motherwell, W.D.S.; Cole, J.C. DASH: A program for crystal structures determination from powder diffraction data. J. Appl. Cryst. 2006, 39, 910-915. [CrossRef]

45. Turner, M.J.; McKinnon, J.J.; Wolff, S.K.; Grimwood, D.J.; Spackman, P.R.; Jayatilaka, D.; Spackman, M.A. CrystalExplorer17; University of Western Australia: Crawley, Australia, 2017. Available online: http: //hirshfeldsurface.net (accessed on 29 April 2020).

(C) 2020 by the authors. Licensee MDPI, Basel, Switzerland. This article is an open access article distributed under the terms and conditions of the Creative Commons Attribution (CC BY) license (http://creativecommons.org/licenses/by/4.0/). 